\title{
Experiência estética e a interface nos jogos digitais: a produção de um edutainment game - Lua
}

Aesthetic experience and the interface in digital games The production of an edutainment game - Moon

Cristiano Natal Tonéis ${ }^{63}$

Artigo recebido em para publicação em nov/2012 e aceito para publicação em dez/2012

\section{Resumo}

Nesta pesquisa apresentamos um dos principais aspectos na produção de um game, as interfaces, conhecidas como HUD's (Heads-Up Display). Mostraremos uma breve evolução na história dos jogos digitais bem como os avanços em sua produção para ampliar os efeitos imersivos nos jogos digitais. Enfatizamos formas para o desenvolvimento de uma interface inteligente (Boschetti, 2001), e assim procuramos contribuir com desenvolvedores Indie utilizando técnicas presentes em grandes produções e demonstrando seus exemplos e evoluções no game Lua - nosso game protótipo.

Palavras-chave: Interface, experiência estética, edutainment game.

\section{Abstract}

In this research, we present one of the principal aspects of games. The interfaces or better knew by the acronym HUD's (Heads-Up Display). We are going to show the succinct evolution in the history of games suffered by them as well as the advance in their production in order to amplify or affect positive the immersion in digital games. We emphasize forms and ways of developing what we consider an intelligent interface (Boschetti, 2001), in order to help the INDIE developers we are going to use and present some techniques from the major productions as well as showing examples and evolutions of game Lua - our game prototype.

Keywords: Interface, aesthetic experience, edutainment game.

\footnotetext{
${ }^{63}$ Cristiano Natal Tonéis é Doutorando em Educação Matemática (Uniban/SP) - Tecnologias Digitais e Educação Matemática - sob orientação da Prof. Drâ. Janete Bolite Frant. É Mestre em Tecnologias da Inteligência e Design Digital (PUC/SP) e Graduado em Matemática pela UNESP. Pesquisador em games na educação e desenvolvimento de games e/ou aplicativos com potencial para educação. É professor de Matemática Aplicada aos Jogos Digitais e orientador de projetos de Iniciação Científica junto as Faculdades Metropolitanas Unidas FMU/SP. E-mail: cristoneis@gmail.com
} 


\section{Introdução}

Os games evidenciam a constante evolução das tecnologias digitais seja por meio da qualidade gráfica, das animações e efeitos (sonoro/visuais) bem como a forma pela qual o jogador é convidado a jogar, "ao longo das últimas três décadas, os jogos progrediram das simulações de rebatidas simplórias à sofisticação de Final Fantasy" (Maciel e Venturelli 2004, p.170). Assim, apresentamos nesta pesquisa um estudo aplicado fundamentalmente na interação homem/máquina ou ainda jogador/jogo, a interface ou HUD (Heads-Up Display).

Autores como Federoff (2002), O'Brien (2010) e Boschetti (2001), entre outros nos indicam caminhos seguros a seguir na construção de uma interface "inteligente" e somando esforços ao conceito de edutainment game traçamos nossa metodologia e aplicação no desenvolvimento do game Lua (nosso edutainment game em desenvolvimento). Nos jogos digitais além de aspectos que se assemelham ao nosso mundo, como o som de nossos passos ou de nossa respiração que fazem parte de nossa "paisagem sonora", temos elementos adjacentes como é o caso da pontuação, vida, mana, resistência etc. Moroni (2011, p.4) afirma que uma "interface limpa auxilia o jogador a focar em seus objetivos e que sua fácil compreensão e funcionalidade são fatores vitais para garantir o sucesso de uma interface".

Desta forma, observamos que na produção de um game devemos nos atentar também para sua apresentação quanto interface, pois gradualmente ampliando sua qualidade objetiva estamos colaborando para a imersão do jogador.

Com isso, a seguir, situamos nossa pesquisa e nossos objetivos, seguidos de um breve histórico das interfaces nos games bem como aplicamos tal revisão ao game Lua e apontamos em nossas considerações para ações futuras que serão apresentadas no game e em publicações.

\section{Trabalhos relacionados}

Diversas pesquisas apresentam questões referentes à produção e análise de interfaces, tais como Federoff (2002), O'Brien (2010), Moroni (2011) entre outros. Nossa proposta encontra-se na unidade interface/game, buscando um referencial histórico para produção de um edutainment game em sua versão protótipo - Lua.

\section{Objetivo}

Desenvolver um edutainment game - Lua - protótipo digital, traçando para este um método de planejamento de interface inteligente.

3.1 Objetivos específicos:

$\checkmark$ Demonstrar a evolução das interfaces, e sua relevância para os jogos digitais; 
$\checkmark$ Verificar a importância e influência da interface para experiência estética e para um edutainment game.

$\checkmark$ Oferecer subsídios e procedimentos para criação e desenvolvimento de interfaces inteligentes;

\section{Breve histórico das interfaces em jogos digitais}

As interfaces, também conhecidas como HUD's são responsáveis por transmitir ou comunicar os feedbacks do jogo ao usuário. Ora, desta forma desejamos que ao entrar em um jogo o jogador transmute-se como parte dele, eis o princípio imersivo do jogo, e será a interface nosso portal de entrada e comunicação com o jogo, por isso a clareza e a objetividade devem ser aspectos considerados no momento de construirmos uma HUD. Exemplificamos com dois jogos paradigmáticos (figura 01) ambos do ano de 1993, Myst e Doom.
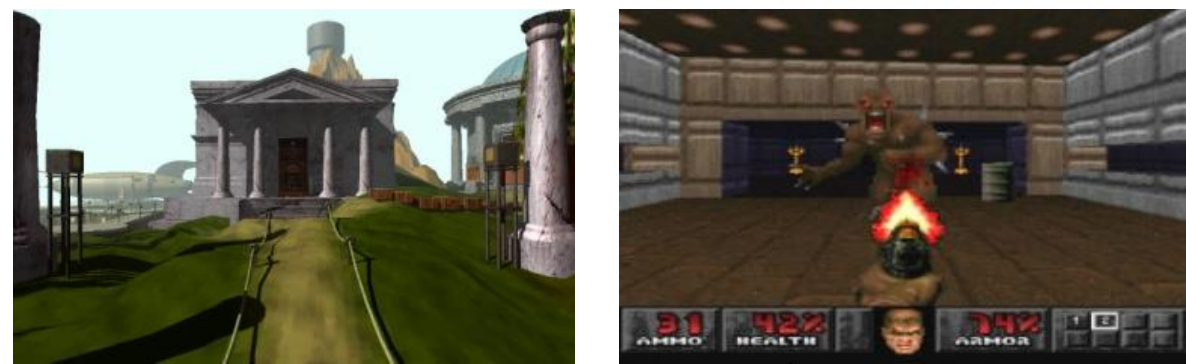

Figura 01: A esquerda Myst I - Jardim e Biblioteca. A direita cena de Doom.

Para Manovich (2001) estes são jogos referenciais particularmente pelo design e pelo espaço navegável, cada qual com suas particularidades, Myst como um mundo aberto o qual possui uma jogabilidade mais lenta permitindo-se explorar calmamente cada detalhe do ambiente e cenário, a respeito da interface (HUD) de Myst quase invisível proporcionando grande efeito imersivo, comparável a imersão fílmica Em Doom, a jogabilidade é mais rápida e os mapas são direcionados, labirínticos, o jogador não possui tempo para explorar o mapa, pois seu objetivo primordial é derrotar os inimigos. Os mapas são formados por boxes ou caixas que imprimem a impressão de um espaço maior do que realmente é. Em Doom a interface apresenta vários elementos como vida, munição, colete, pois caracteriza-se como um jogo de ação/ficção. Este modelo estendeu-se na produção de diversos games, com elementos os quais ocupam boa parte da tela. Não podemos afirmar que ao ponto de tonar a HUD "poluída" visualmente, porém este modelo pode encobrir partes do cenário. Temos o exemplo de Doom (1993); Top Gear (1992) e Mario Kart: Super Circuit (2001) - figura 02. 



Figura 02: A esquerda Top Gear (1992). À direita Mario Kart: Super Circuit (2001).

Podemos observar (figura 02) o que afirmávamos, pois temos diversos elementos na interface como velocidade, circuito, número de voltas, além do cenário e seus elementos próprios. Outros games utilizam uma boa alternativa posicionando a câmera dentro do carro e a velocidade passa a ser representada no próprio velocímetro do carro (interface integrada ao jogo)

Alguns pesquisadores, como Federoff (2002) e O'Brien (2010), identificam técnicas que podem auxiliar na produção de uma interface "limpa". Com base em propriedades que emergem nos jogos mais recentes, essa tendência da interface dos jogos está em utilizar uma Interface Aplicada ao Mundo de jogo (no HUD), a principal característica dessa técnica é encontrar uma maneira para incluir ou integrar a interface como objeto ao cenário ou ambiente (environment) do jogo. Muitos jogos fazem isso para adicionar, ampliar ou proporcionar uma maior sensação de imersão, também como tentativa de adicionar qualidade artística ao jogo. Para exemplificar o que é uma Interface Integrada ao mundo de jogo temos Dead Space (figura 03), sua interface aproxima-se de uma "qualidade fílmica", como a inaugurada por Myst (Miles 1999, p.309).

O protagonista possui uma roupa especial a qual mostra a barra de vida do jogador, localizada na coluna vertebral do personagem - roupa - e o contador de munição é projetado sobre cada arma quando o personagem esta mirando e o inventário é apresentado em uma espécie de holograma que o personagem também pode ver.
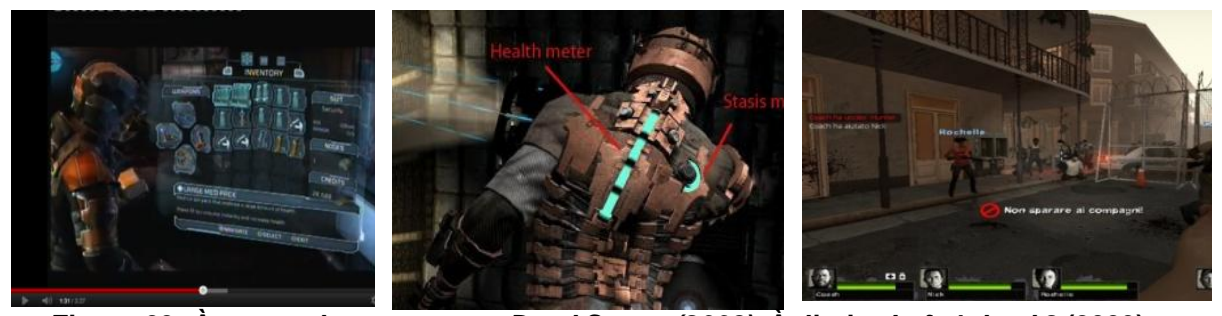

Figura 03: À esquerda e ao centro Dead Space (2008). A direita Left 4 dead 2 (2009).

Fagerholt e Lorentzon (2009) utilizam uma terminologia para tipos diferentes de interfaces, sendo eles: 
[1] Diegética: Interface que está incluído no mundo do jogo, ou seja, ele pode ser visto e ouvido pelos personagens do jogo. Exemplo: a interface holográfica em Dead Space.

[2] Não-diegética: Interface que é prestado fora do mundo do jogo, apenas visível e audível para os jogadores do mundo real. Exemplo: elementos clássicos $(H U D)$.

[3] Espacial: Elementos de interface do usuário apresentado no espaço do jogo em 3D, com ou sem ser uma entidade do mundo real do jogo (diegética ou não diegética). O personagem em Left 4 Dead (figura 03) é um exemplo de não-diegética UI espacial.

[4] Meta Representações são elementos que podem existir no mundo do jogo, mas não estão necessariamente visualizados espacialmente para o jogador. $O$ exemplo mais evidente são efeitos apresentados diretamente na tela, como manchas de sangue na câmara para indicar danos ou ferimentos graves - Mortal Kombat do PS Vita - ou ainda "visão" embasada para indicar o status de saúde.

\section{A interface e os edutainment games: uma perspectiva histórica}

Para Hutchison (2007) os games educacionais (chamados muitas vezes de edutainment) são um tipo de serious game, apesar de já serem utilizados em sala de aula bem antes da expressão serious games ${ }^{64}$ ter sido criada.

O aprendizado baseado em jogos digitais (Digital Game-Based Learning, DGBL) como apresentado por Prensky (2007) baseia-se em duas premissas: [1] os aprendizes mudaram em diversos pontos fundamentais; [2] eles compõem uma geração que experienciou profundamente, enquanto crescia, pela primeira vez na história, uma forma radicalmente nova de jogar - computadores e video-games.

Poderemos então compreender que assistimos a uma descontinuidade, inclusive na maneira como essas gerações aprendem. Torna-se necessário uma revisão, em boa parte dos dados que colhemos e das teorias que formulamos no passado, principalmente a respeito de como pensamos e aprendemos,pois dada tal descontinuidade tais informações podem não mais serem aplicáveis. Neste movimento continuo do pensamento humano torna-se necessário admitirmos e considerarmos novos estilos de aprendizagem ${ }^{65}$. DGBL, não é o único método, porém

\footnotetext{
${ }^{64} \mathrm{~A}$ atual definição de "jogos sérios" parece seguir o conjunto liderado por Sawyer \& Rejeski (2002). No entanto, o oxímoro "jogos sérios" foi aplicado anteriormente com um significado semelhante. Podemos, inclusive, supor que alguns dos primeiros jogos foram projetados para servir a propósitos sérios. "O primeiro uso do oxímoro 'Serious Game' com um significado próximo de seu uso atual parece estar em 'Serius Games', um livro escrito por Clark Abt (1970)" (DJAOUTI, D. et al., 2011, p.2).

65 Patricia Marks Greenfield, professora de psicologia da Universidade da California (Los Angeles), estudou os diversos efeitos do uso de video-games nos jovens de hoje, que desenvolveriam habilidades como ler imagens visuais, habilidades cognitivas, descoberta de
} 
apresenta-se como um método que consegue atingir essa nova geração e apresenta-se para além de atividades de revisão como um modo para um aprendizado efetivo de diversos temas, assim como o que apresentamos no game Lua, a cultura e o universo indígena, segundo uma visão também literária ${ }^{66}$. Agregando valores interdisciplinares no mesmo espaço, o game.

Apresentamos a seguir uma pequena trilha histórica desta presença do edutainment game no ambiente escolar:

[1] The Oregon Trail $^{67}(1971)$ : este game e m si traduz a história das interfaces (evoluindo, em 40 anos, de folhas impressas até uma versão para celulares) é um jogo de decisão e originalmente projetado para ser utilizado nas escolas e ensinar as crianças a respeito da vida no século 19 (na trilha percorrida pelos pioneiros de Independence, no Missouri, a Willamette Valley, no Oregon - Oregon Trail). Produzido posteriormente pela Minnesota Educational Computing Consortium (1974). O jogador assume o papel do líder da caravana de colonos até o Missouri e teria que superar desafios como atravessar rios, caçar búfalos, conseguir água e defender-se de pistoleiros, atravessar regiões com cobras, etc.

[2] Where in the World is Carmen Sandiego? ${ }^{68}$ (1985): Um jogo que ficou mundialmente conhecido, primeiramente pela personagem misteriosa e inteligente Carmen que não efetua roubos nada convencionais e depois pelo desafio que ela faz ao jogador para capturá-la. Viajamos por diferentes países do globo, reconhecendo monumentos e locais históricos, como agentes secretos, seguindo pistas e procurando por Carmen Sandiego ${ }^{69}$.

[3] Mario is Missing! (1993): No enredo deste jogo, Mario é capturado e Luigi, então irá resgatá-lo. Controlando Luigi, o jogador vaga por cidades do mundo e deve responder perguntas a respeito de geografia afim de avançar para os próximos estágios, existem outras guests tais como

regras, compreensão de simulações científicas e divisão da atenção em diferentes tarefas (Prensky, 2007).

${ }^{66}$ Como veremos adiante o game protótipo Lua traz referencias literárias da primeira fase do romantismo Brasileiro, em particular a trilogia indianista escrita por José de Alencar (O Guarani, Iracema e Ubirajara).

67. Criado pelos professores Don Rawitsch, Bill Heinemann e Paul Dillenberger entre os títulos de games criados para educação o único sancionado pelo governo e inserido no currículo escolar americano que ensinava para as crianças a obscura "conquista do oeste americano" (Disponível em: <http://jarbas.wordpress.com/2011/01/26/simulacoes-em-educacao-exemploclassico/>).

${ }^{68}$ A primeira versão do game foi de 1985 mas devido ao grande sucesso evoluiu e ganhou novas versões ampliando seus temas mais recentemente Camen resurge em "Carmen Sandiego adventures in Math" (janeiro 2012), agora também para Nintendo Wii (Houghton Mifflin Harcourt and The Learning Company. Carmen Sandiego Adventures in Math. Em $<$ http://www.hmheducation.com/games/index.php>. Acesso em 26 out 2012).

\footnotetext{
${ }^{69} \mathrm{Na}$ década de 90 estréia também na televisão brasileira uma série de desenhos animados da Carmen (cartoons), intitulada "Where on Earth is Carmen Sandiego?", ou seja "Em que lugar do mundo está Carmen Sandiego?". (Fonte: Carmen Sandiego: Official Game Site. Disponível em: $<\mathrm{http}: / / \mathrm{www}$. carmensandiego.com $/ \mathrm{hmh} / \mathrm{site} /$ carmen/home/articles?article $=43143>$. Acesso em 25 out. 2012.
} 
devolver relíquias, que são patrimônio histórico, a seus respectivos países. Em cada cidade, existem várias pessoas espalhadas pelas ruas, e colaboram com dicas a respeito do país onde Luigi se encontra. Ao compreender as dicas, o jogador deve ir ao Globulator $^{70}$ e lá deve localizar o país controlando Yoshi.

Prensky (2007, p.97) apresenta uma frase do célebre Seymour Papert $^{71}$, "game designers compreendem melhor a natureza da aprendizagem do que os designers de currículos"72. Ora na busca por uma metodologia de criação para interface de "jogos educativos" a fim de rompermos antigos paradigmas nacionais que marcaram esta categoria como Boring nos torna imprescindível nesta pesquisa apresentarmos um panorama renovado para esta categoria de jogos. Neste sentido, somamos com títulos como:

$\checkmark \quad$ Mata Atlântica, o bioma onde eu moro (UFSC)

$\checkmark \quad$ Tríade (UNEB)

$\checkmark$ A estrada Real (UFMG)

$\checkmark$ Portugal 1111-A Conquista de Soure (Universidade de Coimbra)

$\checkmark$ Calangos (UFBa)

$\checkmark \quad$ City Rain (Unesp-Bauru)

Estes games foram desenvolvidos com a intervenção de pesquisadores (universidades) e denotam o interesse e a relevância da produção acadêmica e pesquisas sistematizadas nesta área.

Não possuímos a intenção de esgotar as perspectivas históricas na produção de interfaces, desejamos apenas aproximarmos nossa pesquisa e nosso jogo em desenvolvimento (Lua) e nas palavras de Lévy (1996, p.16) o virtual não se opõe ao real, mas sim ao atual, ou seja "o virtual constitui a entidade: as virtualidades inerentes a um ser, sua problemática, o nó de tensões, de coerções e de projetos que o animam, as questões que o movem, são uma parte essencial de sua determinação", desta forma o mundo virtual demanda a potencialidade do sujeito, provocando-o ao passo que nos reinventamos nele, é neste ponto que apontamos para este novo "formato" de jogo educativo ou edutainment game e particularmente em seu aspecto quanto interface, ligação ou inter-relação homem/máquina.

\section{Aplicações das Interfaces}

Lúcia Santaella (2003) considera que a interface é um ponto de contato no qual softwares interligam o jogador humano aos processadores do computador e estes intensificam e modificam nosso poder de pensamento e

\footnotetext{
${ }^{70}$ Uma espécie de globo terrestre no universo do jogo.

${ }^{71}$ Criador da linguagem LOGO de programação, conhecida mundialmente como "geometria da tartaruga".

${ }^{72}$ Tradução nossa, texto original: "Game designers have a better take on the nature of learning than curriculum designers" (Prensky, 2007, p.97).
} 
para isso, o ser humano precisa estar plugado e por outro lado a tecnologia nos incorpora. Compreendemos então que uma interface realiza um encontro, mesmo sendo este da face de uma pessoa com a face de uma tela, neste sentido a interface realiza a conexão entre universos. Em concordância, Manovich (2001) nos ensina que a interface é uma forma ou espécie de tradutor ou mediador entre o homem e a máquina, assim ainda que um usuário não conheça um determinado sistema, jogo ou aplicativo é possível utilizar-se de sua intuição para decifrar as metáforas na tela, isso devido à apresentação do conteúdo que geralmente tende a proporcionar uma ligação metafórica com situações ou ferramentas físicas do mundo real. Federoff (2002) nos indica algumas recomendações de game design sintetizando e compilando diversas pesquisas, categorizou três importantes áreas para se planejar um jogo: Interface, Mecânicas de jogo e game play. Destacamos a interface e as seguintes características, por serem relevantes e com maior influência em nossa pesquisa e protótipo:

$\checkmark \quad$ A interface não deve ser intrusiva;

$\checkmark \quad O$ jogador deve ser sempre capaz de identificar seu status e pontuação, se houver, durante o jogo;

$\checkmark \quad$ Procure seguir alguns dos padrões e sugestões das comunidades de jogadores a fim de reduzir a curva de aprendizado da jogabilidade e interface em si;

$\checkmark \quad$ O design da interface deve ser consistente quanto ao tema do jogo, controle, cor, tipografia, diálogos;

$\checkmark \quad$ Os feedbacks (Sons, efeitos visuais etc.) são importantes;

Encontramos um excelente exemplo na série de games GTA, que pode ser entendida como uma referência na evolução das interfases, desde sua primeira versão até a mais recente, aplicando e integrando recursos como redução de informações visualizadas pelo jogador, utilização de iconografia e citamos ainda a série Myst, denotando muitos dos aspectos que elencamos acima. Assim, estabelecemos uma estreita relação entre as interfaces e a experiência estética no interior dos games, buscando elementos que promovam um método de produção para tais interfaces.

\section{Lua: Estudo na criação de uma interface inteligente para um edutainment game.}

Para Munari (1998), o design é a área do conhecimento que tem como principal atividade a síntese do novo, por meio da aplicação adequada de métodos e técnicas visando à concepção de objetos inovadores. Ao refletirmos a respeito da importância destes elementos para um game, verificamos que para desenvolvermos uma interface necessitamos compreender primeiramente seu significado e relevância em todo projeto.

Assim como outros autores citados, Johnson (2001, p.17) afirma que em seu sentido mais simples, a palavra se refere a "softwares que dão forma à interação entre usuário e computador". A interface atua como uma espécie de tradutor, mediando entre duas partes, tornando uma sensível para a outra. Em outras palavras, a relação governada pela interface é uma 
relação semântica, caracterizada por significado e expressão, não pela força física.

Podemos assim compreender que uma interface inteligente é uma interface planejada segundo critérios de design e jogabilidade, citemos: apresentar-se prazerosa para o jogador; ser amigável, de fácil utilização (intuitiva); esteticamente agradáveis e também divertidas. Uma interface inteligente pode contribuir para experiências estéticas no interior do game (Tonéis 2010) ao passo que colaborem no processo de aprendizagem do jogo, do novo universo a ser descoberto, ou seja, para momentos de apreciação e construção de conhecimentos oferecidos neste universo alternativo - metaverso. Utilizando-se de algumas das técnicas citadas nesta pesquisa, o desenvolvimento de um game (protótipo) - Lua - com os concepts dos personagens, cenários e interface inteligente (Boschetti, 2001), visa tal experiência no mundo virtual e aproveitando-se destes recursos para criação de um edutainment game, pois é exatamente neste ponto que repousa nossa perspectiva de aplicação do estudo de interfaces inteligentes, produzir um game, no qual somos convidados a vivenciar momentos de exploração, construção de heurísticas para superar puzzles, e simultaneamente entramos em contato com um universo novo e estranhamente familiar ${ }^{73}$ da cultura indígena.

Lua é um edutainment game de aventura, ambientado em um mundo fictício inspirado uma floresta tropical repleta de vida - flora e fauna - bem como seus habitantes nativos e cultura. O jogo possui level design labirintico ${ }^{74}$ e cuja navegação é motivada por quests e pela resolução de puzzles lógicos e desafios em batalhas, possibilitando ao jogador explorar um vasto cenário $3 D$, além de possuir elementos narrativos do estilo $R P G$, oferecendo uma rica experiência em interatividade e diversão. Sua narrativa encontra-se fundamentada no início do Romantismo no Brasil (1836), na qual segundo Romero (1888) encontramos a ideia de tornar o indígena o centro das atenções, seja no poema ou na prosa. Inspirados principalmente pela proposta de Ferdinand Denis e de Gonçalves de Magalhães, os romancistas e poetas brasileiros produziram uma extensa obra na qual o índio é visto como um grande herói da nação. Nesse sentido, podemos citar o famoso poema "Juca Pirama", de Gonçalves dias, e a trilogia indianista escrita por José de Alencar ( $O$ Guarani, Iracema e Ubirajara) bem como elementos da cultura indígena apresentado em Santos (1974) e pela web Page da FUNAI.

Inspirados por esta proposta é que a o game Lua desenrola-se no coração de uma floresta tropical, onde nosso herói - Jaci (figura 04) - irá

\footnotetext{
${ }^{73}$ Desde muito cedo na vida escolar os aprendizes estão sujeitos a encontrar elementos folclóricos, este na visão do homem branco. Na perspectiva indígena não existem mitos, tudo é real e segundo Olívio Jekupé, índio guarani e autor do livro "O Saci Verdadeiro" (JEKUPÉ, Olívio. O Saci Verdadeiro. Londrina: Editora UEL, 2000).

74 . LEÃO, Lucia . O labirinto da hipermídia: Arquitetura e navegação no ciberespaço. 3.ed. São Paulo: lluminuras, 2005.
} 
enfrentar todos os obstáculos para salvar sua amiga e amada Cunhataí desvendando os mistérios da floresta e da história de sua tribo.

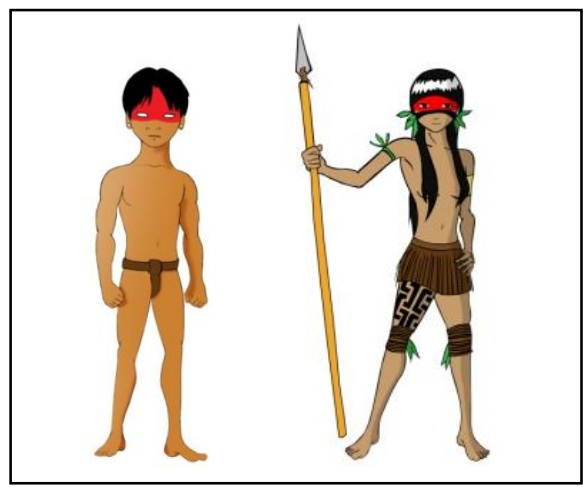

Figura 04: Concept art de Jaci - o herói - e Cunhataí, produção de Lucas Tadeu.

A produção da interface no projeto iniciou-se com o pressuposto de aplicarmos em larga escala elementos dinâmicos que ultrapassem os usuais. Por meio de pesquisas com a experiência estética e imersão digital (Murray 1998; Tonéis 2010) e nossa observação e análise dos jogos que apresentamos, objetivamos alcançar uma produção equivalente as de alto orçamento (high-budget games). Ao passo que ao experimentamos essas técnicas estaremos aprendendo e ampliando as possibilidades de sucesso de nosso projeto. Como um planejamento inicial proposto para produção do protótipo Lua elencamos alguns aspectos importantes e notáveis em nossa concepção de "interface limpa" buscando o conceito de interface inteligente: menu lateral iconográfico, pentagonal com pequenas circunferências contendo ícones com elementos do game (figura 05); a caixa de diálogos é transparente para não sobressair ao próprio universo do jogo e apenas será apresentada em caso de diálogos (figura 05).

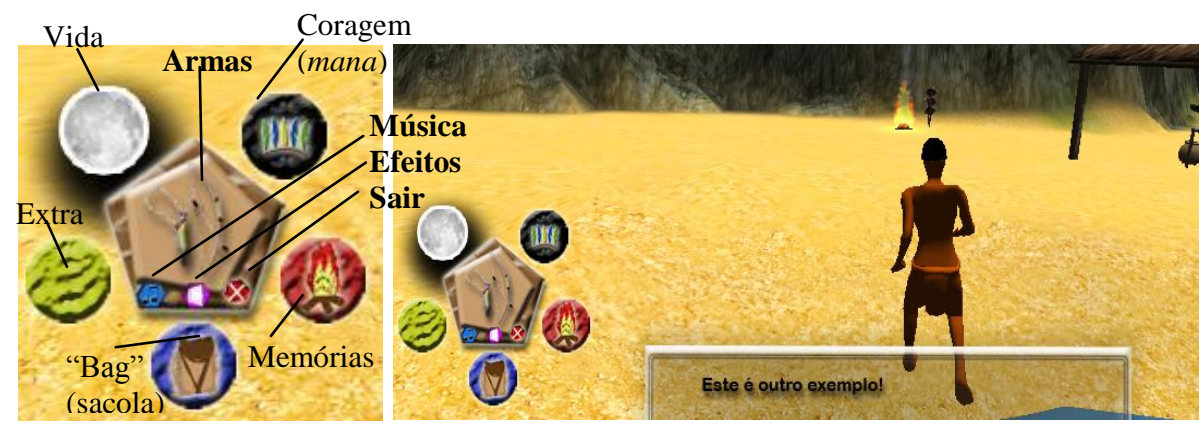

Figura 05: Lua (Protótipo): À esquerda ampliação do detalhe da interface. À direita interface do Jogo com seus elementos e caixa de diálogo ilustrativa. Produzida por Lucas Tadeu. 
Em particular apresentamos o ícone "Memórias" representado por uma fogueira, este ícone será o responsável pela inclusão e motivação da narrativa ao game, pois ao se encontrar com algum personagem ou local do game no local da fogueira aparecerá uma face, seja do pajé, um ancião ou um amigo da tribo, o que ocorrerá é uma breve apresentação de fatos ligados ao personagem ou local, seja por meio de um cinematic ${ }^{75}$. A vida possuirá o formato de uma lua variando em suas fases (lua nova, quarto crescente, lua cheia e quarto minguante) de acordo com a proporção de vida. Classificamos como coragem a energia espiritual que será necessária na luta contra espíritos malignos da floresta. A sacola servirá para o transporte de itens em pequenas quests. O módulo "extra" em versões futuras oferecerá ao jogador a possibilidade de fotografar uma paisagem do game, um personagem ou animal e enviar a foto para a comunidade virtual do Facebook. As armas para o jogador serão o arco e flecha (contra inimigos naturais) e o chocalho do pajé (contra os inimigos sobrenaturais). Assim no planejamento e elaboração da interface do jogo manifestamos o propósito da simplicidade e clareza das informações como os pequenos botões para sair, efeitos sonoros e música (liga/desliga)

Tendo nossa fundamentação teórica autores como O'Brien (2010) e o Federoff (2002) entre outros citados, podemos afirmar que a interface deve ser "invisível" produzindo e conduzindo para o jogo, ícones permitem velocidade ao passo que textos podem causar confusão além de lentidão na compreensão pelos jogadores e caso existam cenas, devemos permitir que o jogador "pule" se assim desejar. Por isso a necessidade de planejarmos e produzirmos um diagrama da interface, pois desejamos facilitar e transformar o processo de produção do game em algo transparente e acessível aos profissionais envolvidos, definindo as telas necessárias do jogo; favorecendo o design e "onde e quando" possível otimizar ou aperfeiçoar os gráficos; os esboços e descrições no diagrama (figura 06) são uma referência e um modelo na produção gráfica.

\footnotetext{
${ }^{75}$ Neste ponto apresentaremos uma variação de cinematics, sejam pequenas animações feitas com "homens palitos", seja uma voz ao redor de uma fogueira contando uma história, seja uma lembrança em tons de cinza ou ainda um mni-game. Nosso desejo é motivar o jogador a assistir as diferentes apresentações que poderão ajudá-lo a desvendar os mistérios da história de LUA, contribuindo para construção da narrativa do game.
} 


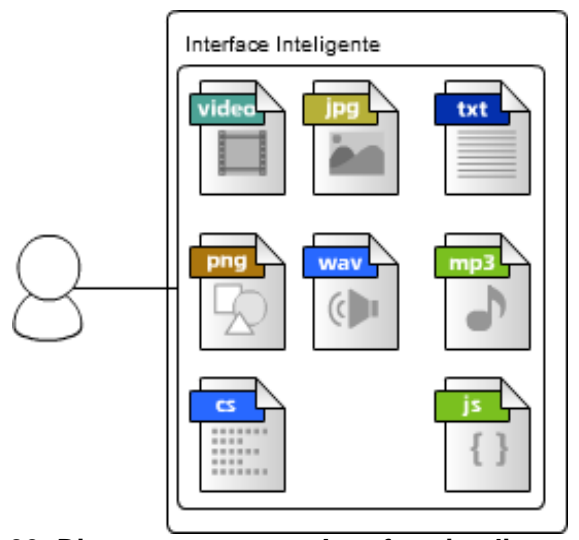

Figura 06: Diagrama para uma Interface inteligente utilizando o maior número possível de efeitos.

Podemos afirmar que no desenvolvimento funcional das interfaces prezamos pelas informações relevantes e com isso ocuparmos o mínimo possível de espaço em tela. Uma interface com informação vital para o jogo pode estar visível permanentemente.

Mattar (2010) critica a escola atual, pois em seu entendimento "o aprendizado necessita de motivação para um envolvimento intenso, o que é atingido pelos games" neste sentido Prensky (2007) afirma que games geram envolvimento como nenhuma outra mídia, o que se deve a vários fatores: diversão, jogo, regras e estrutura, objetivos, interatividade, resultados e feedback, fluxo etc. Propõe também alguns princípios do "bom design" de games para computadores: balanceado (nem muito difícil nem muito fácil), criativo, focado, personagens, tensão e energia, além de vários outros elementos também interessantes: uma visão geral clara, foco constante na experiência do jogador, uma estrutura sólida, altamente adaptativo, fácil de aprender, mas difícil de dominar, permanece no estado de fluxo, fornece recompensa constante - não penalidades, inclui exploração e descoberta, fornece assistência mútua - uma coisa ajuda a resolver outra - e que possua uma interface muito útil e inclui a habilidade para salvar o progresso. Em Lua este check point será automático em pontos estrategicamente situados no mapa do jogo, recorrendo a feedbacks sonoro e visual para indicar o salvamento da posição do jogador.

\section{Considerações finais: Tendências para a produção de interfaces}

Podemos afirmar que atualmente algumas das tendências para a produção de interfaces estão na exploração de nossos sentidos, para além da visão a audição e as texturas apresentam-se como um reforço para as experiências táteis e estéticas nos games. No caso específico dos jogos eletrônicos, os sons são itens indispensáveis e de suma importância para experiência vivida no interior do game, enriquecendo-a além das fronteiras que seriam 
atingíveis apenas com gráficos bem elaborados (Ribeiro et al, 2009), pois desenham uma paisagem sonora para o universo que estamos explorando e descobrindo, proporcionando-nos uma experiência próxima ao universo fílmico.

Certamente que as técnicas cinematográficas sempre influenciarão a produção de jogos digitais convertendo-os em um "laboratório experiencial" verificando a ampliação dos efeitos imersivos no jogador. Nas palavras de Paiva (2012) "a realidade virtual é uma grande descoberta que tem raiz nos sonhos", efetivamente, a realidade virtual é um colocar em prática aquilo que nós queremos imaginar. Nosso desejo de vivenciar nossos sonhos nos conduz a criamos novos mundos e nos impulsionam na produção de universos virtuais progressivamente realistas no sentido de proporcionar experiências estéticas, e estas indispensáveis quando o formato do jogo é "educativo".

Nossa pesquisa e desenvolvimento de Lua encontra-se em implementação, ou seja, nas ações de: modelagem, animação, efeitos visuais/sonoros - aplicações na engine (Unity $3 D$ ) assim nossos objetivos não foram atingidos em sua totalidade, nas próximas etapas do projeto (level design, programação/versão demo, design test/game tester) esperamos que, quanto protótipo, seja possível observamos nossos esforços para a produção de uma interface amigável e limpa e desta forma contribuirmos para uma metodologia na criação desta nova geração de "jogos educativos".

\section{Agradecimentos}

A equipe de produção do game Lua: Lucas Tadeu, Felipe Lemos, Felipe Corral, Ivo Alsleben Cegantini e Talles Fernando, graduandos em Jogos Digitais - FMU/SP - e aceitaram o desafio de transformar seu trabalho de conclusão de curso em um edutainment game que ainda sendo um protótipo se apresenta desafiador.

\section{Referências}

BETHKE, E. Game development and production. Wordware Publishing, 2003.

BOMFIM, G. A. Idéias e formas na história do design: uma investigação estética. João Pessoa: Universitária - UFPB, 1998.

BOSCHETTI, M. N. Arquiteturas Para Interfaces Inteligentes. Porto Alegre: Universidade Federal do Rio Grande do Sul, 2001. Disponível em <http://www.inf.ufrgs.br/procpar/disc/cmp135/trabs/012/T1/smart/smart.htm\# _Toc527892877>. Acesso em 22 jun. 2012. 
BRAGA, A. S. Design de interface: As origens do design e sua influência na produção de hipermídia. Revista Comunicação e Semiótica. Pontifícia Universidade Católica de São Paulo. 2004.

DJAOUTI, D.; ALVAREZ, J.; JESSEL, J.P.; RAMPNOUX, O. Origins of Serious Games. In Serious Games and Edutainment Applications. Springer, 2011, pp.25-43.

DONOVAN, T. Replay: The History of Video Games. Great Britain: Yellow Ant, 2010.

FAGERHOLT, E.; LORENTZON, M. Beyond the HUD: User Interfaces for Increased Player Immersion in FPS Games. Department of Computer Science and Engineering - Division of Interaction Design. Chalmers University of Technology. Göteborg, Sweden, 2009.

FEDEROFF, M. Heuristics and Usability Guidelines for the Creation and Evaluation of Fun in Video Games. Tese de Mestrado, Indiana University, 2002. Disponível em: <http://melissafederoff.com/thesis.html>. Acesso em 10 fev 2012

FOX, B. Game Interface Design. Boston, MA: Thomson Course Technology, 2005.

GIDDINGS, S. Walkthrough: Videogames and Technocultural Form. University of the West of England, Bristol. Maio 2006.

HOGLE, J. G. Considering Games as Cognitive Tools: In Search of Effective "Edutainment". University of Georgia - Department of Instructional Technology. August 1996.

HUTCHISON, D. Playing to learn: video games in the classroom. Westport, CT: Libraries Unlimited, 2007.

JOHNSON, D. M.; WILES, J. Effective affective user interface design in games. $\quad$ Ergonomics. $2010 . \quad$ Disponível em $<$ http://citeseerx.ist.psu.edu/viewdoc/download?doi=10.1.1.91.2491\&rep=rep 1 \&type $=$ pdf $>$. Acesso 03 fev 2012

JOHNSON, S. A cultura da Interface. Rio de Janeiro: Ed. Jorge Zahar, 2001.

LÉVI, P. O que é o Virtual ? São Paulo: Editora 34 Ltda, 1996.

MACIEL, M.; VENTURELLI, S. Games. Conexão - Comunicação e Cultura, UCS, Caxias do Sul, v. 3, n. 6, 2004, pp. 167-190. 
MATTAR, J. Games em Educação: como os nativos digitais aprendem. São Paulo: Pearson, 2010.

MANOVICH. L. Espaço Navegável. Revista Comunicação e Linguagens, Lisboa. Universidade Livre de Lisboa, 34. 2005, pp. 109-141.

MILES, D. The CD-ROM Novel Myst and McLuhan's Fourth Law of Media: Myst and its "Retrievals". Em: Mayer, Paul (org.). Computer Media and Communication: a Reader. Oxford (NY): Oxford University Press, 1999, pp. 307-319.

MORONI, L. M.; BATTAIOLA, A. Heads-up Display integrados ao universo de um jogo eletrônico. SBC - Proceedings of SBGames 2011 (Art \& Design). Acesso em 28 jan 2012.

MUNARI, B. Das coisas nascem coisas. Martins Fontes, São Paulo, 1998.

MURRAY, J. H. Hamlet no Holodeck: O Futuro da Narrativa no Ciberespaço. Tradução de Elissa Khoury Daher, Marcelo Fernandez Cuzziol. São Paulo: Itaú Cultural, Unesp, 2003.

O'BRIEN, P. Interactive Games Design: IGD130 Games Production. Week 5 - Interface Design for Games. University of Gloucestershire, 2010. Disponível em: <http://gmedia.glos.ac.uk/igd130/igd130wk5.pdf>. Acesso em 04 abr 2012.

PAIVA, T. Sonhos têm "impacto" na sociedade e podem conduzir a importantes criações. Ciência Hoje: Jornal da Ciência, Tecnologia e Empreendedorismo. $\quad$ Abr $2012 . \quad$ Em $<$ http://www.cienciahoje.pt/index.php?oid=53711\&op=all>. Acesso em 02 abr 2012.

PRENSKY, M. Digital game-based learning: practical ideas for the application of digital game-based learning. St. Paul, MN: Paragon House, 2007.

RIBEIRO, B.; LUCCHESE, F.; CASTAÑEDA, Z. Interfaces de Jogos Digitais. 2009. Disponível em: <http://www.dca.fee.unicamp.br/ martino/disciplinas/ia369/trabalhos/t3g3.pd f>. Acesso em 04 abr 2012.

ROMERO, S. História da literatura brasileira. v.1. Rio de Janeiro: BL Garnier, 1888.

SANTAELLA, L. Culturas e artes do pós-humano: Da cultura das mídias à cibercultura. São Paulo: Paulus, 2003. 
SANTOS, T.M. Lendas e Mitos do Brasil. 4.ed. São Paulo: Nacional, 1974.

TONÉIS, C. N. A logica da descoberta nos jogos digitais. Dissertação de Mestrado em Tecnologias da Inteligência e Design Digital. Pontifícia Universidade Católica de São Paulo, 2010.

WEILLER, T. A. Jogos digitais: Interfaces gráficas e interação. Revista Eletrônica Temática. Ano VI, n. 10, Outubro de 2010. Em <http://www.insite.pro.br>. Acesso em 04 abr 2012. 